\title{
Effect of CBL Combined with Case Analysis in the Teaching of Clinical Anesthesia
}

\author{
Yuming Zhang1, Fei Xue ${ }^{2 *}$ \\ ${ }^{1}$ Department of Anesthesiology, Shaanxi Provincial People's Hospital, Xi'an 710068, Shaanxi Province, China \\ ${ }^{2}$ Department of General Surgery, Shaanxi Provincial People's Hospital, Xi'an 710068, Shaanxi Province, China \\ *Corresponding author: Fei Xue, zhangyum2021@163.com
}

\begin{abstract}
Objective: To evaluate the effect of CBL (case-based learning) combined with case analysis in the teaching of clinical anesthesia. Methods: From June 2018 to June 2020, a total of 100 clinical anesthesia interns in Shaanxi Provincial People's Hospital were selected as the research subjects. They were divided into two groups, the reference group (50 interns) and the study group (50 interns), by random sampling method. The reference group was under the traditional teaching method, whereas for the study group, CBL combined with case analysis was implemented. The teaching satisfaction and achievement of the interns in both the groups were evaluated. Results: The teaching satisfaction of the study group was $98 \%$, which was significantly higher than that of the reference group $(86 \%)(P<0.05)$; before teaching, there was no significant difference in the theoretical and clinical practice scores between the two groups $(P>0.05)$; however, after teaching, the theoretical and clinical practice scores of the two groups increased significantly, in which the change of the research group was significantly greater than that of the reference group $(P<0.05)$. Conclusion: The application of CBL combined with case analysis in the teaching of clinical anesthesia has an ideal effect, improving the teaching satisfaction and achievement. It is a high-quality teaching method and is worthy of application.
\end{abstract}

Keywords: CBL; Case analysis; Clinical anesthesia; Teaching satisfaction; Teaching achievement

Publication date: December 2021; Online publication: December 27, 2021

\section{Introduction}

Clinical anesthesia is an important part of anesthesiology education. It is an important link in the comprehensive training of medical students in terms of their basic knowledge, basic theory, and basic skills. Anesthesia related technology plays an important role in the development of the hospital and the safety of patients. It will not only affect the employment prospects of medical students, but also the professional strength of a hospital ${ }^{[1]}$. In the teaching of clinical anesthesia, the traditional teaching method is mainly implemented. Interns would visit the department and follow their teachers to observe and learn until the end of their practice. This teaching method ensues a difficulty in promoting the cultivation of clinical thinking and the mastering of skills among interns. A comparative study was conducted, in which 100 clinical anesthesia interns in Shaanxi Provincial People's Hospital were evaluated. Different teaching methods were implemented after random sampling and grouping.

\section{Materials and methods}

\subsection{General information}

The research subjects were selected from Shaanxi Provincial People's Hospital from June 2018 to June 2020. A total of 100 clinical anesthesia interns met the inclusion criteria of the research. After random 
sampling and grouping, in which they were divided into two groups, a research group and a reference group, with 50 interns in each group, different teaching methods were implemented. In the reference group, there were 19 female interns and 31 male interns, age ranging from 22 to 27, with a mean age of $24.57 \pm 2.37 ; 8$ interns with bachelor's degree, and 42 interns with qualifications higher than a bachelor's degree. In the study group, there were 17 female interns and 33 male interns, age ranging from 22 to 27, with a mean age of $22.59 \pm 2.61 ; 11$ interns with bachelor's degree and 39 interns with bachelor's degree or above. There was no significant difference between the two groups based on their baseline information $(P>0.05)$.

\subsection{Methods}

The reference group was under the traditional method of teaching, which mainly involved teaching according to syllabus, forming teaching plans with computers, fully preparing teaching materials, designing relevant problems according to the teaching contents, preparing review questions for interns, and evaluating the teaching effect.

CBL combined with case analysis was implemented for the interns in the study group. The implementation of this method was as follows: (1) preparation before class; before teaching, the teacher would select relevant anesthesia videos of patients of different ages and different types of surgeries according to the progress of the syllabus as well as fully prepare the cases; then, the interns would be divided into groups of ten, and one of them would be selected as the group leader; the day prior to the class, the interns would be informed of the teaching content, and relevant cases would be distributed to the interns, requiring the interns to search for relevant materials before the class; (2) classroom teaching; during the class, the teacher and the interns would watch the videos together, put forward relevant problems according to the cases, discuss and learn in groups, as well as analyze the problems in combination with the data collected prior to the class; (3) class discussion; the group leader would take charge of the discussion, and the group members would have the opportunity to express their views; after the discussion, the group leader would summarize the group's discussion, and the teacher would provide his or her feedback; (4) comprehensive feedbacks; based on the discussion, the teacher would comment on the summarized discussion and help the interns to effectively master the key contents, effectively identify and diagnose diseases, answer cardinal questions, analyze the key and difficult points, as well as summarize the teaching results.

\subsection{Observation indexes}

(1) Teaching satisfaction

In order to evaluate the satisfaction of the interns toward the teaching work, the teaching satisfaction questionnaire that was constructed by the department was used. The evaluation was as follows: very satisfied (86-100 points), generally satisfied (51-85 points), and dissatisfied ( $\leq 50$ points).

(2) Teaching achievement

Before and after the implementation of the teaching, the performances of the interns were assessed. The assessment contents were clinical practice performance and theoretical performance. The score range was $0-100$ points. The score is positively correlated with the assessment score.

\subsection{Statistical analysis}

All the data were analyzed using SPSS 23.0 software. Chi-square $\left(x^{2}\right)$ test (counting data) and t-test (measurement data) were carried out. The counting data were expressed as $[\mathrm{n} /(\%)]$, and the measurement data were expressed as $\bar{x} \pm \mathrm{S} . P<0.05$ indicates a statistical difference. 


\section{Results}

\subsection{Teaching satisfaction}

The teaching satisfaction of the study group was $98 \%$, which was higher than that of the reference group $(86 \%)$. The difference was statistically significant $(P<0.05)$, as shown in Table 1.

Table 1. Comparison of the teaching satisfaction between the two groups $[\mathrm{n} /(\%)]$

\begin{tabular}{ccccc}
\hline Group & Dissatisfied & General satisfied & Very satisfied & Satisfaction \\
\hline Study group $(\mathrm{n}=50)$ & $1(2)$ & $12(24)$ & $37(74)$ & $49(98)$ \\
Reference group $(\mathrm{n}=50)$ & $7(14)$ & $15(30)$ & $28(56)$ & $43(86)$ \\
$x^{2}$ & -- & -- & -- & 4.891 \\
$P$ & -- & -- & -- & 0.027 \\
\hline
\end{tabular}

\subsection{Teaching achievement}

Before teaching, there was no significant difference in the theoretical scores and clinical practice scores between the two groups $(P>0.05)$. However, after teaching, the theoretical scores and clinical practice scores of the two groups increased significantly, in which the change of the research group was greater than that of the reference group. The difference between the two groups was statistically significant $(P<0.05)$, as shown in Table 2.

Table 2. Comparison of the teaching scores between the two groups (points)

\begin{tabular}{ccccc}
\hline \multirow{2}{*}{ Group } & \multicolumn{2}{c}{ Theoretical scores } & \multicolumn{2}{c}{ Clinical practice scores } \\
\cline { 2 - 4 } & Before teaching & After teaching & Before teaching & After teaching \\
\hline Research group $(\mathrm{n}=50)$ & $78.43 \pm 5.75$ & $92.42 \pm 3.31$ & $76.26 \pm 5.47$ & $93.54 \pm 2.69$ \\
Reference group $(\mathrm{n}=50)$ & $78.25 \pm 5.58$ & $89.59 \pm 3.45$ & $76.49 \pm 5.33$ & $91.67 \pm 2.73$ \\
$\mathrm{t}$ & 0.159 & 4.185 & 0.213 & 3.450 \\
$P$ & 0.874 & 0.000 & 0.832 & 0.001 \\
\hline
\end{tabular}

\section{Discussion}

Clinical anesthesiology is not only a practical subject in clinical medicine but also a comprehensive subject of intensive care, clinical anesthesia, pain diagnosis and treatment, first aid, as well as resuscitation. In anesthesiology teaching, clinical anesthesia is an important link, which does not only require medical students to have solid theoretical foundation and knowledge, but also to master important operating skills ${ }^{[2]}$. CBL is a case-based teaching model, which can promote teaching satisfaction, improve teaching achievements and the weight of teaching, as well as effectively cultivate the participants' ability to analyze and solve problems ${ }^{[3]}$. CBL combined with case analysis is a new teaching method; this teaching method places the participants as the center in the whole teaching process. Through the guidance of teachers, students can give full play to their subjective initiative and promote the improvement of their analysis as well as problem-solving skills. Taking clinical cases as the teaching basis and making full use of the learned knowledge in this method, the participants' clinical thinking can be expanded, thus improving the teaching effect ${ }^{[4]}$. This research showed that the teaching satisfaction of the study group was $98 \%$, which was significantly higher than that of the reference group (86\%) $(P<0.05)$. In addition, before teaching, there was no significant difference in the theoretical scores and clinical practice scores between the two groups $(P>0.05)$; however, after teaching, the theoretical scores and clinical practice scores of both the groups 
increased significantly, but the change of the research group was significantly greater than that of the reference group $(P<0.05)$.

In conclusion, the implementation of CBL combined with case analysis in the teaching of clinical anesthesia has an ideal effect, which can promote the improvement of teaching satisfaction and teaching achievement. It is a high-quality teaching method and is worthy of promotion.

\section{Disclosure statement}

The authors declare that there is no conflict of interest.

\section{References}

[1] Zhao Z, Wang S, 2020, Application of Participatory Teaching in Clinical Anesthesia Practice. Chinese Journal of Medical Education Research, 19(07): 844-846.

[2] Yin S, Wu W, Qin G, 2020, Application Effect of Phased Teaching Mode in Clinical Anesthesia Practice Teaching. Clinical Research and Practice, 5(04): 182-183.

[3] Zhang J, Guo J, 2021, Application Effect of CBL Combined with PDCA Cycle Teaching Mode in the Regulation and Training of General Practitioners in Rheumatology Department. Modern Medicine \& Health, 37(18): 3214-3216.

[4] Liang Y, Chen X, Liang X, et al., 2020, Analysis of the Application Effect of Case-based Learning (CBL) and Problem-Based Learning (PBL) in Nursing Teaching Methods in the Cultivation of Nurses' Core Competence. Capital Medicine, 27(07): 112-113. 